\title{
Non-Singlet Oxygen Kinetic Solvent Isotope Effects in Aquatic Photochemistry
}

\author{
Caroline A. Davis, ${ }^{\dagger, \ddagger}$ Kristopher McNeill, ${ }^{*}, \oplus$ and Elisabeth M.-L. Janssen $*,+\infty$ \\ ${ }^{\dagger}$ Institute of Biogeochemistry and Pollutant Dynamics, ETH Zurich, Zürich, 8092, Switzerland \\ ${ }^{\ddagger}$ Swiss Federal Institute of Aquatic Science and Technology, Eawag, Dübendorf, 8600, Switzerland
}

Supporting Information

\begin{abstract}
The kinetic solvent isotope effect (KSIE) is typically utilized in environmental photochemistry to elucidate whether a compound is susceptible to photooxidation by singlet oxygen $\left({ }^{1} \mathrm{O}_{2}\right)$, due to its known difference in lifetime in water $\left(\mathrm{H}_{2} \mathrm{O}\right)$ versus heavy water $\left(\mathrm{D}_{2} \mathrm{O}\right)$. Here, the overall indirect photodegradation rates of diarylamines in the presence of dissolved organic matter (DOM) were enhanced in $\mathrm{D}_{2} \mathrm{O}$ to a greater extent than expected based on their reactivity with ${ }^{1} \mathrm{O}_{2}$. For each diarylamine, the relative contribution of reaction with ${ }^{1} \mathrm{O}_{2}$ to the observed KSIE was determined from high resolution data of ${ }^{1} \mathrm{O}_{2}$ lifetimes by timeresolved infrared luminescence spectroscopy. The additional enhancement in $\mathrm{D}_{2} \mathrm{O}$ beyond reaction with ${ }^{1} \mathrm{O}_{2}$ contributed significantly to the observed KSIE for diarylamines $(8-65 \%)$ and diclofenac $(100 \%)$. The enhancement was ascribed to slower reduction of transient radical species of the diarylamines due to $H / D$ exchange at DOM's phenolic antioxidant moieties. A slower second-order reaction

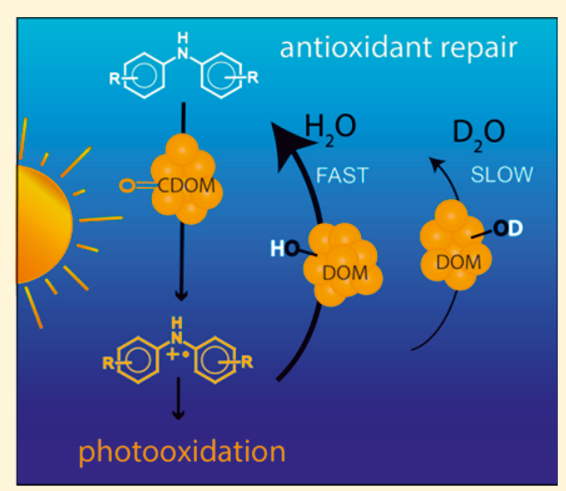
rate constant with a model antioxidant was verified for mefenamic acid radicals using transient absorption spectroscopy. Changes in lifetime and reactivity with triplet sensitizers were not responsible for the additional KSIE. Other pollutants with quenchable radical intermediates may also be susceptible to such an additional KSIE, which has to be considered when using the KSIE as a diagnostic tool.
\end{abstract}

\section{INTRODUCTION}

Singlet oxygen $\left({ }^{1} \mathrm{O}_{2}\right)$ is a reactive oxygen species present in sunlit surface waters at steady-state concentrations ranging from $10^{-12}$ to $10^{-14} \mathrm{M} \cdot{ }^{1-4}{ }^{1} \mathrm{O}_{2}$ is formed through an energy transfer reaction between ground state oxygen $\left({ }^{3} \mathrm{O}_{2}\right)$ and photochemically produced excited triplet states of ubiquitous chromophoric dissolved organic matter (CDOM). Energy transfer to ${ }^{3} \mathrm{O}_{2}$ occurs for most excited triplet states since the required energy to promote ${ }^{3} \mathrm{O}_{2}$ to ${ }^{1} \mathrm{O}_{2}$ is low $\left(E_{\mathrm{S}}=94 \mathrm{~kJ}\right.$ $\left.\mathrm{mol}^{-1}\right) .^{5-7}$ The major reaction pathways of singlet oxygen include $[2+2]$ and $[2+4]$ cycloaddition, ene reactions, and phenol and sulfide oxidation reactions. ${ }^{8}$ Thus, several organic compounds can be oxidized by ${ }^{1} \mathrm{O}_{2}$, including cyclic dienes, polycyclic aromatic compounds, and heterocycles, as well as olefins containing allylic hydrogen atoms. ${ }^{9-11}$ Due to its specific reactivity with chemical probes, e.g., furfuryl alcohol, ${ }^{12-14}$ characterizing indirect photodegradation due to ${ }^{1} \mathrm{O}_{2}$ has become a standard technique in the environmental photochemist's toolbox. In addition, a kinetic solvent isotope effect (KSIE) has been relied upon as a diagnostic test to identify the reactivity of organic compounds with ${ }^{1} \mathrm{O}_{2}$. ${ }^{4,15-20}$ This KSIE manifests itself in an acceleration of the observed degradation rate for a compound of interest when the solvent is changed from $\mathrm{H}_{2} \mathrm{O}$ to $\mathrm{D}_{2} \mathrm{O}$. While the mechanisms of the KSIE for ${ }^{1} \mathrm{O}_{2}$ are well understood, other photochemical transformation pathways could have their own solvent isotope effects, and evidence for both is detailed below.
The major deactivation pathway of ${ }^{1} \mathrm{O}_{2}$ results from energy transfer to the solvent, and a KSIE for ${ }^{1} \mathrm{O}_{2}$ results from a longer ${ }^{1} \mathrm{O}_{2}$ lifetime in $\mathrm{D}_{2} \mathrm{O}(67 \mu \mathrm{s})^{21}$ versus $\mathrm{H}_{2} \mathrm{O}(3.6 \mu \mathrm{s}) .{ }^{22}$ The vibrational frequencies of $\mathrm{H}_{2} \mathrm{O}$ align with the electronically excited energy of ${ }^{1} \mathrm{O}_{2}$ causing an efficient deactivation by transferring the correct quanta of energy. In $\mathrm{D}_{2} \mathrm{O}$, the vibrational frequencies are shifted, the energy transfer from ${ }^{1} \mathrm{O}_{2}$ becomes less efficient, and solvent deactivation slows down $\left(k_{\mathrm{d}}{ }^{1 \mathrm{O} 2}\right.$ in Figure $\left.1 \mathrm{~A}\right) .^{23}$ As a consequence, in $\mathrm{D}_{2} \mathrm{O}$ steady-state concentrations of ${ }^{1} \mathrm{O}_{2}$ are higher, while the bimolecular reaction rate constants of ${ }^{1} \mathrm{O}_{2}$ with compounds of interest are generally not affected. ${ }^{14}$

In photochemistry, the diagnostic test to evaluate the reactivity of an organic pollutant with ${ }^{1} \mathrm{O}_{2}$ relies on this ${ }^{1} \mathrm{O}_{2}$ specific KSIE. Therefore, the degradation rates of the compound of interest are measured in aqueous samples containing CDOM as a natural sensitizer, with and without enrichment of $\mathrm{D}_{2} \mathrm{O}$. The ratio of the rate constants in $\mathrm{H}_{2} \mathrm{O}$ (unenriched) and in $\mathrm{D}_{2} \mathrm{O}$-enriched samples presents the observed KSIE, (KSIE ${ }_{\mathrm{obs}}$, and is indicative of the contribution of ${ }^{1} \mathrm{O}_{2}$. The method requires, however, that neither the secondorder reaction rate constant of other oxidants with the

Received: March 21, 2018

Revised: July 10, 2018

Accepted: July 29, 2018

Published: July 30, 2018 


\section{A. Lifetimes of oxidants}

(independent of compound of interest)

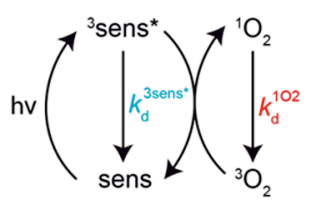

B. Bimolecular reaction rate constants (dependent on compound of interest)

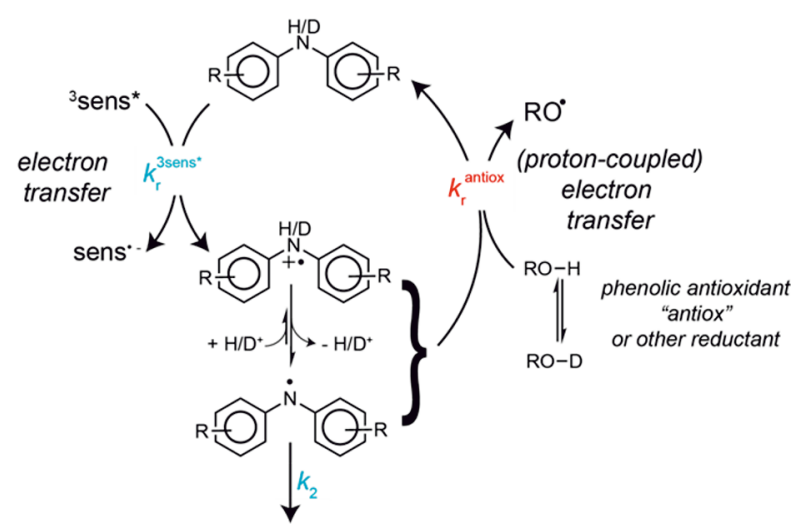

Figure 1. Schematic illustrating the processes that were investigated for a kinetic solvent isotope effect (KSIE). Panel (A) Lifetimes of oxidants: Excited triplet sensitizer $\left({ }^{3}\right.$ sens $\left.{ }^{*}\right)$ and singlet oxygen $\left({ }^{1} \mathrm{O}_{2}\right)$. The ${ }^{3}$ sens* is produced when a chromophoric organic compound (i.e., sensitizer) absorbs a photon of light $(\mathrm{h} v)$ and ${ }^{1} \mathrm{O}_{2}$ is formed when the ${ }^{3}$ sens* transfers energy to molecular oxygen $\left({ }^{3} \mathrm{O}_{2}\right)$. The native lifetimes of the oxidants are inversely proportional to the solvent deactivation rates $\left(k_{\mathrm{d}}\right)$, which may be $\mathrm{D}_{2} \mathrm{O}$ sensitive, as known for ${ }^{1} \mathrm{O}_{2}$. The native lifetimes of oxidants are independent of the compound of interest. Panel (B) Second-order reaction rate constants with the compound of interest, i.e., substituted diarylamines. The ${ }^{3}$ sens* reacts with diarylamines, producing a radical intermediate that can oxidize further $\left(k_{2}\right)$. The radical intermediate can react with phenolic antioxidant moieties via a (proton-coupled) electron transfer (PCET) to regenerate the parent compound. H/D exchange with the solvent by the phenolic antioxidant may affect the second-order quenching rate constant $\left(k_{\mathrm{r}}^{\text {antiox }}\right)$ and exchange at reactive moieties of the ${ }^{3}$ sens* $^{*}$ or at the compound of interest may affect the second-order oxidation rate constants $\left(k_{\mathrm{r}}^{3 \operatorname{sen} s *}\right)$.

compound of interest nor the oxidants' steady-state concentrations change during $\mathrm{D}_{2} \mathrm{O}$-enrichment. Consequently, the method can be misleading for chemicals of interest that participate in non- ${ }^{1} \mathrm{O}_{2}$ reactions that are $\mathrm{D}_{2} \mathrm{O}$-sensitive.

Other $\mathrm{D}_{2} \mathrm{O}$-sensitive reaction pathways may, however, contribute to the KSIE, including oxidation reactions by photochemically excited triplets and reduction reactions of radical intermediates. The reaction with excited triplets may show a KSIE if deactivation of the triplet by the solvent and thereby the triplet steady-state concentration changes in $\mathrm{D}_{2} \mathrm{O}$ $\left(k_{\mathrm{d}}^{3 \text { sens* } *}\right.$ in Figure 1A), e.g., due to altered vibrational coupling with the solvent, analogous to ${ }^{1} \mathrm{O}_{2}$. For example, the triplet lifetimes of methylene blue and substituted ruthenium(II) bipyridyl complexes are longer in $\mathrm{D}_{2} \mathrm{O}$ versus $\mathrm{H}_{2} \mathrm{O} \cdot{ }^{24,25}$ In addition the second-order reaction rate constant between excited triplets and the compound of interest could change depending on the solvent, which would also result in a KSIE $\left(k_{\mathrm{r}}^{3 \text { sens } *}\right.$ in Figure 1B). Specifically, when the triplet mediated oxidation involves hydrogen abstraction from the compound of interest, an increase in the bond strength for isotopologues with deuterium substitution results in higher dissociation energies and potentially slower reactivity. ${ }^{26-28}$ Also, thermally induced reorganization of the solvent for outer sphere electron transfers can depend on solvent polarization, which determines the free activation energy, and thereby the reaction rate.

Another reaction that could exhibit a KSIE is the reduction of radical intermediates. Oxidation of several pollutants proceeds through radical intermediates, as observed for direct photochemical ionization reaction of tryptophan ${ }^{29}$ and triplet sensitizer-mediated oxidation of anilines, ${ }^{30-32}$ sulfonamide antibiotics, ${ }^{33}$ beta blockers, ${ }^{18}$ and various pesticides, including chloroacetamide and phenylurea herbicides ${ }^{34}$ and finally diarylamines ${ }^{35}$ that we focus on herein. Reactive intermediates can be reduced back to parent compounds via an electron transfer (ET) or a proton-coupled electron transfer (PCET) pathway by a suitable reductant also termed antioxidant hereafter. Phenolic moieties, known to be the major electron donating groups in DOM, are able to reduce radical intermediates and are readily susceptible to $\mathrm{H} / \mathrm{D}$ exchange. ${ }^{30,33,35,36}$ Accordingly, if the effectiveness for PCET of an antioxidant is decreased in $\mathrm{D}_{2} \mathrm{O}\left(k_{\mathrm{r}}^{\text {antiox }}\right.$ in Figure $\left.1 \mathrm{~B}\right)$, then the observed decay rate of a compound of interest in the presence of antioxidants would be enhanced in $\mathrm{D}_{2} \mathrm{O}$.

The presented work investigates the overall $\mathrm{KSIE}_{\mathrm{obs}}$ for photochemical reactions to elucidate the contribution of other reaction pathways beyond ${ }^{1} \mathrm{O}_{2}$. Several diarylamine-based pharmaceuticals frequently detected in surface waters were selected as test compounds because they not only undergo oxidation by ${ }^{1} \mathrm{O}_{2}$ but also react with excited triplet sensitizers to form radical intermediates that can be reduced back to the parent compound by a suitable antioxidant. ${ }^{35,37-40}$ First, the $\mathrm{KSIE}_{\mathrm{obs}}$ was quantified for CDOM sensitized reactions in batch steady-state photoexperiments. Next, the contribution of ${ }^{1} \mathrm{O}_{2}$ to the $\mathrm{KSIE}_{\mathrm{obs}}$ was determined using high resolution data of ${ }^{1} \mathrm{O}_{2}$ lifetimes relative to $\mathrm{D}_{2} \mathrm{O}$ concentrations. Finally, the additional non-singlet oxygen KSIE was examined for contributions from other reaction pathways. Transient absorption spectroscopy verified that an additional KSIE arises from lower reactivity of phenolic antioxidants to reduce the radical intermediate of the compound of interest.

\section{EXPERIMENTAL SECTION}

Materials and Solutions. Experiments were carried out in buffer from potassium phosphate dibasic (Sigma-Aldrich, $\geq 98 \%$ ) and potassium dihydrogen phosphate (Fluka, $\geq 99.5 \%$ ). Aqueous solutions were prepared with ultrapure water (>18 M $\Omega \mathrm{cm}$, Barnstead Nanopure Diamond system). The following reagents were purchased from Sigma-Aldrich and used as received: 3'-methoxyacetophenone (97\%), acetonitrile (HPLC grade), caffeic acid ( $\geq 98 \%)$, deuterium chloride solution ( 35 wt \% in $\mathrm{D}_{2} \mathrm{O}, 99$ atom \% D), diclofenac sodium salt $(\geq 98.5 \%)$, lumichrome, potassium deuteroxide solution ( $40 \mathrm{wt} \%$ solution in $\mathrm{D}_{2} \mathrm{O}, 98+$ atom\% D), sesamol $(98 \%)$, sodium acetate trihydrate $(\geq 99.0 \%)$, superoxide dismutase from bovine erythrocytes (BioReagent $\geq 3,000$ units/mg protein), and tolfenamic acid. Dry acetonitrile was prepared using $\mathrm{CaH}_{2}$ and stored under argon. Flufenamic acid (97\%) was purchased from Acros Organics. Acetic acid $(\geq 99.8 \%)$ and mefenamic acid $(\geq 98 \%)$ were obtained from Fluka. Furfuryl alcohol (Merck, $\geq 98 \%$ ) was distilled and kept under argon to avoid oxidation until use. Acetonitrile- $\mathrm{d}_{3}$ (99 atom \% D) and deuterium oxide (99.8 atom \% D) were 
purchased from Armar Isotopes. Suwannee River Fulvic Acid (2S101F) was purchased from the International Humic Substance Society (IHSS, stock solutions at $85 \mathrm{mg}_{\mathrm{C}} \mathrm{L}^{-1}$ in $\mathrm{H}_{2} \mathrm{O}$ and $\mathrm{D}_{2} \mathrm{O}$, were kept frozen until use). AlphaGaz $1 \mathrm{Ar}$ (99.999\% purity) and AlphaGaz $2 \mathrm{O}_{2}$ (99.9995\% purity) were purchased from Carbagas AG.

Steady-State Photodegradation Experiments. The $\mathrm{KSIE}_{\mathrm{obs}}$ during photochemical degradation was investigated for five compounds, individually: diclofenac, mefenamic acid, tolfenamic acid, meclofenamic acid, and flufenamic acid. Photochemical experiments were conducted under three different conditions: phosphate buffered solution, in the presence of natural DOM, and in the presence of a model sensitizer.

For tests with DOM, samples contained $5 \mu \mathrm{M}$ of the compound of interest, $10 \mathrm{mg}_{\mathrm{C}} \mathrm{L}^{-1}$ SRFA, and $40 \mu \mathrm{M}$ FFA buffered at $\mathrm{pH} / \mathrm{D} 8$ (phosphate buffer, $5 \mathrm{mM}$ ) in $0.81-0.94$ (mole fraction, $\chi \mathrm{D}_{2} \mathrm{O}$ ) or $1.00\left(\chi \mathrm{H}_{2} \mathrm{O}\right)$ (natural abundance of $\mathrm{D}_{2} \mathrm{O}$ approximately $\left.0.015 \%\right){ }^{41}$ The exact fraction of $\mathrm{D}_{2} \mathrm{O}$ was assessed with the FFA probe (see data in SI, Table S1). Samples were irradiated in open borosilicate test tubes with enhanced UVA light (12 bulbs, centered at $365 \mathrm{~nm}$ ) on a turntable in a Rayonet photoreactor (Southern New England Ultraviolet Company, Branford, USA) with a polymer heat/ bandpass filter situated between the lamps and the samples to remove light below $320 \mathrm{~nm}$ and also long wavelengths above 400 nm (269 LEE Heat Shield, Lee Filters, Hampshire, UK). Aliquots were taken over time in triplicate and analyzed for the compound of interest and FFA as described previously. ${ }^{35}$ Oxygen-free tests were performed in stoppered test tubes that were sparged with argon gas for $15 \mathrm{~min}$ prior to irradiation. To test for the impact of superoxide radical anion, 75 units $\mathrm{mL}^{-1}$ superoxide dismutase was added to the reaction mixture (diclofenac only).

For the test with model sensitizer, DOM was replaced by $0.77 \mu \mathrm{M}$ perinaphthenone, and the light exposure was reduced because kinetics proceeded faster due to higher triplet and ${ }^{1} \mathrm{O}_{2}$ steady state-concentrations (2 UVA bulbs). For diclofenac, an additional test was performed with model sensitizer and an antioxidant, $10 \mu \mathrm{M}$ caffeic acid, present in the same vessel.

Data Analysis. The observed decay rate constants, $k_{\text {obs }}$, were obtained by normalizing the concentration over the time course of the experiments to the respective initial concentration $\left(C_{t} / C_{0}\right)$, which were plotted in the log-normalized form, $\ln \left(C_{t} / C_{0}\right)$ versus exposure time and fitted by a pseudofirst-order linear regression model where the slope represents $k_{\text {obs. }}$. The $\mathrm{KSIE}_{\mathrm{obs}}$ was calculated as the ratio of $k_{\mathrm{obs}}$ in $\mathrm{D}_{2} \mathrm{O}$ over $k_{\text {obs }}$ in $\mathrm{H}_{2} \mathrm{O}$.

When the aqueous solvent is enriched with $\mathrm{D}_{2} \mathrm{O}$, the $\mathrm{KSIE}_{\text {obs }}$ can be a result of the superposition of multiple isotope effects from several processes. To evaluate the effect of other reaction pathways to the $\mathrm{KSIE}_{\mathrm{obs}}$, we determined the contribution of ${ }^{1} \mathrm{O}_{2}$ separately as $\mathrm{KSIE}_{1 \mathrm{O} 2}$ and compared this to the overall $\mathrm{KSIE}_{\mathrm{obs}}$. The KSIE $\mathrm{KO}_{2}$ for a compound of interest (i) depends on the fraction of the overall observed decay that results from reaction with ${ }^{1} \mathrm{O}_{2}, f_{\mathrm{i}, 1 \mathrm{O} 2}$ :

$$
\mathrm{KSIE}_{\mathrm{i}, 1 \mathrm{O} 2}=\mathrm{KSIE}_{\mathrm{FFA}, 1 \mathrm{O} 2} \cdot f_{\mathrm{i}, 1 \mathrm{O} 2}
$$

The $\mathrm{KSIE}_{1 \mathrm{O} 2}$ of FFA, $\mathrm{KSIE}_{\mathrm{FFA}, 1 \mathrm{O} 2}$, presents the maximum value with $f_{\mathrm{i}, 1 \mathrm{O} 2}=1$. Values of $f_{\mathrm{i}, 1 \mathrm{O} 2}$ can be determined as

$$
f_{\mathrm{i}, 1 \mathrm{O} 2}=\frac{k_{\mathrm{r}}^{1 \mathrm{O} 2} \times\left[{ }^{1} \mathrm{O}_{2}\right]_{\mathrm{ss}}}{k_{\mathrm{obs}}}
$$

with the second-order reaction rate constant of the compound with ${ }^{1} \mathrm{O}_{2}, k_{\mathrm{r}}{ }^{1 \mathrm{O} 2}\left(\mathrm{M}^{-1} \mathrm{~s}^{-1}\right)$, the steady-state ${ }^{1} \mathrm{O}_{2}$ concentration, $\left[{ }^{1} \mathrm{O}_{2}\right]_{\mathrm{ss}}(\mathrm{M})$, and the overall observed decay rate constant, $k_{\mathrm{obs}}$ $\left(\mathrm{s}^{-1}\right)$. The values of $k_{\mathrm{r}}{ }^{1 \mathrm{O} 2}$ for diarylamines were previously determined to range from 1.3 to $2.8 \times 10^{7} \mathrm{M}^{-1} \mathrm{~s}^{-1}$. 35 These second-order reaction rate constants should not experience a KSIE assuming that any H/D exchange in the molecule, e.g., at the amine functional group, is not affecting the reaction kinetics with ${ }^{1} \mathrm{O}_{2}$. ${ }^{14}$ The values for $\left[{ }^{1} \mathrm{O}_{2}\right]_{\text {ss }}$ were assessed by the kinetics of the probe molecule FFA assuming that $f_{\mathrm{i}, 1 \mathrm{O} 2}=1$ for FFA according to

$$
\left[{ }^{1} \mathrm{O}_{2}\right]_{\mathrm{ss}}=\frac{k_{\mathrm{obs}, \mathrm{FFA}}}{k_{\mathrm{r}, \mathrm{FFA}}^{1 \mathrm{O} 2}}
$$

with $k_{\mathrm{r}}{ }^{1 \mathrm{O} 2}$ of FFA determined as described previously. ${ }^{14,35}$

The observed decay rate constant, $k_{\mathrm{obs}}$, is equal to the sum of the individual pseudo-first-order decay processes

$$
k_{\text {obs }}=k_{\mathrm{r}}^{1 \mathrm{O} 2}\left[{ }^{1} \mathrm{O}_{2}\right]_{\mathrm{ss}}+k_{\text {direct }}+k_{\text {other }}
$$

with $k_{\text {direct }}$ as the apparent first-order rate constant for direct photodecay, and $k_{\text {other }}$ as the observed decay rate constant by any other processes in addition to the contribution from ${ }^{1} \mathrm{O}_{2}$. The contribution of direct photodegradation $\left(k_{\text {direct }}\right)$ to $\mathrm{KSIE}_{\mathrm{obs}}$ was assessed with additional photodegradation tests in the absence of sensitizer. The contribution of $k_{\text {other }}$ to $\mathrm{KSIE}_{\mathrm{obs}}$ was then calculated according to eq 4 from observed decay rate constants of the fenamates and diclofenac, $k_{\text {obs }}$. Mechanistically $k_{\text {other }}$ includes the reactions with triplet sensitizers and antioxidants or other reductants as detailed in the SI (Text S1).

Transient Absorption Spectroscopy Experiments. Transient absorption spectroscopy was carried out using a pump-probe system (EOS, Ultrafast Systems, Sarasota, USA) with pump pulses produced by a regeneratively amplified Ti:sapphire laser (output of $3.5 \mathrm{~W}$ at $795 \mathrm{~nm}, 1 \mathrm{kHz}$ Solstice, Newport Spectra-Physics, Irvine, USA) and subsequent conversion to the desired wavelength using a TOPAS Optical Parametric Amplifier (Light Conversion, Vilnius, Lithuania) as previously described. ${ }^{35}$ Excitation wavelengths for perinaphthenone, lumichrome, and 3-methoxyacetophenone were 370, 400 , and $320 \mathrm{~nm}$, respectively.

For triplet lifetime measurements, perinaphthenone, lumichrome, and 3-methoxyacetophenone (3-MAP) were tested as model sensitizers with no exchangeable protons, amine proton exchange, and enol tautomer proton exchange, respectively. Preliminary experiments to verify $\mathrm{H} / \mathrm{D}$ exchange and required incubation times in $\mathrm{D}_{2} \mathrm{O}$ were performed with mass spectrometry for lumichrome and ${ }^{1} \mathrm{H}$ NMR and ${ }^{13} \mathrm{C}\left\{{ }^{1} \mathrm{H}\right\}$ NMR for 3-MAP (details in Text S2 and Figures S1-S6).

To assess the triplet lifetimes, solutions were prepared with $100 \mu \mathrm{M}$ triplet sensitizer in $50 \%$ dry acetonitrile and $50 \% \mathrm{H}_{2} \mathrm{O}$ or $\mathrm{D}_{2} \mathrm{O}$ at $\mathrm{pH} / \mathrm{pD} 8$ (phosphate buffer) and $\mathrm{pH} / \mathrm{pD} 13.6$ for 3MAP only. Samples were sparged for $4 \mathrm{~min}$ prior to and during the measurement with either synthetic air or argon. The transient absorbance of the triplet signals was followed at 490, 393 , and $550 \mathrm{~nm}$ for perinaphthenone, lumichrome, and 3$\mathrm{MAP}$, respectively. The native triplet lifetimes were calculated by fitting the exponential decay of the respective delta absorption signals, $\Delta \mathrm{A}$. 
A Furfuryl alcohol + DOM (ambient air) B Diclofenac + DOM (ambient air)

C Diclofenac + DOM (anoxic)
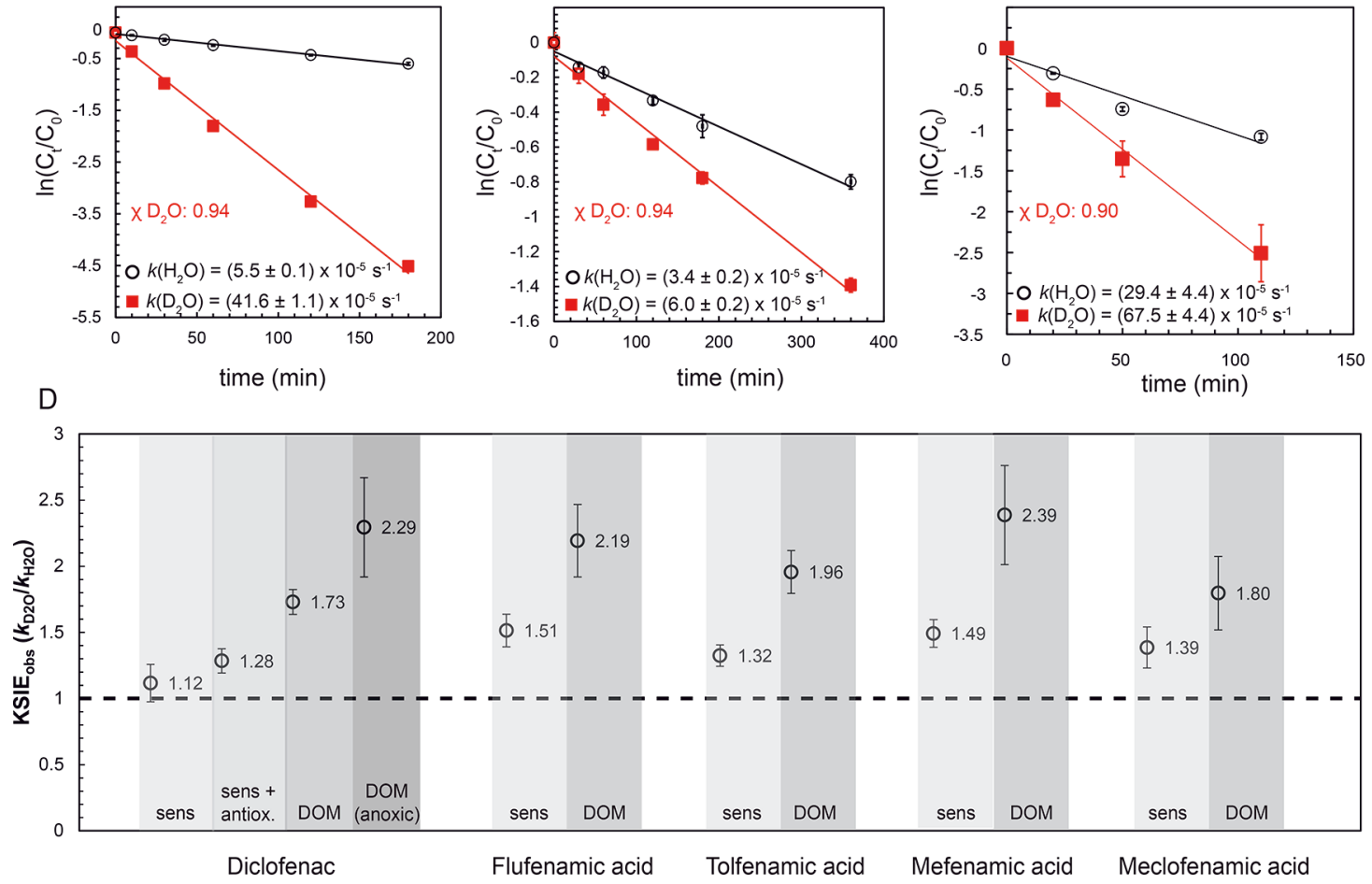

Figure 2. Degradation kinetics during UVA irradiation with dissolved organic matter (DOM) as the triplet sensitizer $\left(10 \mathrm{mg}_{C} \mathrm{~L}^{-1} \mathrm{Suwannee}_{\mathrm{River}}\right.$ Fulvic Acid, SRFA) in buffered aqueous solution (black circles) and enriched with $\mathrm{D}_{2} \mathrm{O}$ (red squares) for furfuryl alcohol (panel A) and diclofenac (panel B). Panel C shows the degradation of diclofenac in DOM, under argon sparged conditions (anoxic). Respective mole fraction of $\mathrm{D}_{2} \mathrm{O}(\chi)$ and pseudo-first-order rate constants $\left(k_{\mathrm{obs}}\right.$, simplified to $k,\left(\mathrm{~s}^{-1}\right)$ in the figure) are presented. The $\mathrm{KSIE}_{\mathrm{obs}}$ as the ratios of pseudo-first-order rate constants, $k_{\mathrm{D} 2 \mathrm{O}} / k_{\mathrm{H} 2 \mathrm{O}}$, are presented for experiments with model triplet sensitizer perinaphthenone (sens, $0.77 \mu \mathrm{M}$ ) and with DOM (SRFA, panel D). For diclofenac, additional experimental data with model sensitizer and the model antioxidant, caffeic acid (10 $\mu \mathrm{M})$, is shown (sens + antiox.). The mole fraction of $\mathrm{D}_{2} \mathrm{O}$ in solutions ranged from 0.81 to 0.94 (for data in panel D). Error bars represent one standard deviation.

Triplet reactivity was determined by adding increasing concentrations $(50-1250 \mu \mathrm{M})$ of mefenamic acid to $100 \mu \mathrm{M}$ lumichrome. The second-order reaction rate constant $\left(k_{\mathrm{r}}^{3 \text { sens* }}\right.$ in $\mathrm{M}^{-1} \mathrm{~s}^{-1}$ ) was assessed as the slope of lumichrome triplet decay rate constants $\left(k_{\mathrm{d}}^{3 \mathrm{sen}} *\right.$ in $\mathrm{s}^{-1}$, the inverse of its lifetime) versus mefenamic acid concentration in a Stern-Volmer plot. Here, lumichrome was chosen as a triplet sensitizer instead of perinaphthenone because its transient triplet signal was more resolved, free of overlapping signals. The triplet intensity $(\Delta \mathrm{A})$ of perinaphthenone and lumichrome showed a linear response with laser power from 1 to $3 \mu \mathrm{J}$ and $1-4 \mu \mathrm{J}$, respectively (Figure S7).

Quenching of the radical intermediate was determined using $100 \mu \mathrm{M}$ lumichrome, $400 \mu \mathrm{M}$ mefenamic acid to generate the radical intermediate, and increasing concentrations of sesamol (25-400 $\mu \mathrm{M})$, a natural phenolic compound, serving as a model antioxidant and quencher for this experiment. Sesamol is a preferred antioxidant for studying reduction of the radical intermediates because it has a low BDFE for the phenolic O$\mathrm{H}$ bond $(341.5 \mathrm{~kJ} / \mathrm{mol})^{28}$ to ensure quenching of the radical and contains only one proton that can exchange with the solvent, reaching maximum deuteration when dissolved in $\mathrm{D}_{2} \mathrm{O}$. The second-order reaction rate constant of the mefenamic acid radical intermediate and antioxidant was derived from the slope of the radical decay rate constants, $k_{\mathrm{d}}$ versus sesamol concentration in a Stern-Volmer plot. All data analysis of the transient experiments was performed using Surface Xplorer 4 (Ultrafast Systems, Sarasota, USA) and Origin Pro 9.0 (Origin Lab Corp. Northampton, MA).
Time-Resolved Infrared Luminescence Experiments. The tests to monitor ${ }^{1} \mathrm{O}_{2}$ phosphorescence were performed as previously described ${ }^{14,35}$ with a regeneratively amplified laser (Solstice, Spectra-Physics, Darmstadt, Germany) which has a pulse width $<100 \mathrm{fs}, 1 \mathrm{kHz}$ repetition rate. Excitation pulses were converted with a TOPAS optical parametric amplifier (Light Conversion, Vilnius, Lithuania) to the desired wavelength of $370 \mathrm{~nm}$. The samples were prepared in triplicate and contained $100 \mu \mathrm{M}$ riboflavin in varying compositions of $\mathrm{D}_{2} \mathrm{O}$ (Table S2). The ${ }^{1} \mathrm{O}_{2}$ phosphorescence was monitored $90^{\circ}$ to the excitation, and the photons emitted passed through a 1270 $\pm 5 \mathrm{~nm}$ bandpass filter, before being detected with a near-IR PMT (Hamamatsu, model H10330-45). Samples were sparged with $\mathrm{O}_{2}$ for $4 \mathrm{~min}$ before and during the experiment. The ${ }^{1} \mathrm{O}_{2}$ signal was fit to an exponential decay function to determine the lifetime under each condition. Singlet oxygen lifetime was independent of laser pulse energy (Figure S8).

\section{RESULTS AND DISCUSSION}

$\mathrm{KSIE}_{\mathrm{obs}}$ from CDOM Sensitized Photodecay. Diclofenac and other diarylamines were selected to investigate evidence of isotope effects on reaction pathways beyond ${ }^{1} \mathrm{O}_{2}$. We showed previously that diarylamines react with triplet state CDOM, and their indirect photochemistry proceeds through a radical intermediate that is quenchable by antioxidants. ${ }^{35}$ The triplet reactivity makes this group of compounds suitable for investigating potential KSIEs for a triplet-related reaction pathway. 
Data in Figure 2 show the pseudo-first-order photodecay in the presence of $10 \mathrm{mg}_{\mathrm{C}} \mathrm{L}^{-1}$ SRFA for the ${ }^{1} \mathrm{O}_{2}$ probe molecule FFA (panel A) and diclofenac (panel B). The observed reaction rate constants $\left(k_{\mathrm{obs}}, \mathrm{s}^{-1}\right)$ demonstrate faster decay in heavy water. Enhanced degradation in $\mathrm{D}_{2} \mathrm{O}$ was observed also for the remaining diarylamines (Figure S9). The $\mathrm{KSIE}_{\text {obs }}$ values are presented for exposure to model sensitizer (sens, $0.77 \mu \mathrm{M}$ perinaphthenone) and organic matter sensitizer (DOM, 10 $\mathrm{mg}_{\mathrm{C}} \mathrm{L}^{-1}$ SRFA, panel D). For all compounds, photodegradation was enhanced in $\mathrm{D}_{2} \mathrm{O}$, as all $\mathrm{KSIE}_{\text {obs }}$ values were larger than 1 . This degradation rate enhancement upon $\mathrm{D}_{2} \mathrm{O}$ enrichment would traditionally be regarded as evidence that the compound of interest reacts with ${ }^{1} \mathrm{O}_{2}$. Although most diarylamines show moderate reactivity toward ${ }^{1} \mathrm{O}_{2}\left(k_{\mathrm{r}}^{1 \mathrm{O} 2}=\right.$ $\left.1.3-2.8 \times 10^{7} \mathrm{M}^{-1} \mathrm{~s}^{-1}\right)$, diclofenac is known to be unreactive with ${ }^{1} \mathrm{O}_{2} \cdot{ }^{35}$ In accordance, only diclofenac showed negligible rate enhancement in $\mathrm{D}_{2} \mathrm{O}$ in the presence of the model sensitizer as a source for ${ }^{1} \mathrm{O}_{2}$, (sens: $\left.k_{\mathrm{D} 2 \mathrm{O}} / k_{\mathrm{H} 2 \mathrm{O}}=1.12 \pm 0.14\right)$. However, a significant enhancement in $\mathrm{D}_{2} \mathrm{O}$ was observed for diclofenac in the presence of CDOM $\left(\mathrm{KSIE}_{\mathrm{obs}}=1.73 \pm 0.09, t\right.$ test, $p<0.05$ ). Contrary to the system with model sensitizer, the CDOM also contains antioxidant moieties that are redox active. $^{36}$ When a model antioxidant was added to the experiment with model sensitizer, the decay for diclofenac was also accelerated in $\mathrm{D}_{2} \mathrm{O}$ (Figure 2D: sens + antiox, $\mathrm{KSIE}_{\text {obs }}$ $=1.28 \pm 0.09$, $t$ test, $p<0.05)$. To provide additional evidence that enhanced degradation in $\mathrm{D}_{2} \mathrm{O}$ was not due to reaction with ${ }^{1} \mathrm{O}_{2}$, a DOM-sensitized test was performed for diclofenac under argon saturated conditions (anoxic, panel $\mathrm{C}$ ), and the degradation was still enhanced in the $\mathrm{D}_{2} \mathrm{O}$ enriched solution.

For all fenamates, the $\mathrm{KSIE}_{\text {obs }}$ was larger in the presence of CDOM as compared to the model sensitizer. These observations of a potential non- ${ }^{1} \mathrm{O}_{2}$-related KSIE in the presence of CDOM led to a detailed investigation to assess whether direct photodecay, reaction with triplet sensitizers, or the reaction of radical intermediates with reducing agents (i.e., antioxidants) was responsible.

The fact that the $\mathrm{KSIE}_{\mathrm{obs}}$ was larger in the presence of DOM, compared to the model sensitizer for all compounds, suggests that an additional reaction pathway other than ${ }^{1} \mathrm{O}_{2}$ contributed to the rate enhancement in $\mathrm{D}_{2} \mathrm{O}$. We first determined the contribution of the reaction with ${ }^{1} \mathrm{O}_{2}$ for each experiment with CDOM to then evaluate the magnitude of the additional KSIE.

Contribution of ${ }^{1} \mathrm{O}_{2}$ Pathway to $\mathrm{KSIE}_{\text {obs. }}$. The dependency of ${ }^{1} \mathrm{O}_{2}$ lifetime on the amount of $\mathrm{D}_{2} \mathrm{O}$ present needs to be considered when disentangling the different reaction pathways contributing to the overall $\mathrm{KSIE}_{\text {obs }}$ in steady-state experiments. While ${ }^{1} \mathrm{O}_{2}$ lifetime, $\tau$, has a well-known dependency on the solvent composition, some inconstancies exist in the literature regarding the exact lifetimes. ${ }^{21,42} \mathrm{We}$ assessed the KSIE on the ${ }^{1} \mathrm{O}_{2}$ lifetime by varying the fraction of $\mathrm{D}_{2} \mathrm{O}$ from 0.0 to 1.0 and measuring decay of the ${ }^{1} \mathrm{O}_{2}$ luminescence signal using state-ofthe-art time-resolved infrared luminescence spectroscopy. Data in Figure 3 show the relationship between the lifetime of ${ }^{1} \mathrm{O}_{2}$, $\operatorname{KSIE}_{1 \mathrm{O} 2}\left(\tau \chi_{\mathrm{D} 2 \mathrm{O}} / \tau_{\mathrm{H} 2 \mathrm{O}}\right)$ and the $\mathrm{D}_{2} \mathrm{O}: \mathrm{H}_{2} \mathrm{O}$ solvent composition, $\chi \mathrm{D}_{2} \mathrm{O}$ (see tabulated data in Table S2; Figure S10). The lifetimes in $100 \% \mathrm{H}_{2} \mathrm{O}$ and $100 \% \mathrm{D}_{2} \mathrm{O}$ were 3.56 and $63.68 \mu \mathrm{s}$ (solvent deactivation rates: $k_{\mathrm{d}}{ }^{1 \mathrm{O} 2}=2.81 \pm 0.07 \times 10^{5} \mathrm{~s}^{-1}$ and $1.57 \pm 0.02 \times 10^{4} \mathrm{~s}^{-1}$ ) respectively. The $\mathrm{KSIE}_{1 \mathrm{O} 2}$ is high, with a maximum enhancement by a factor of 17.9 from $100 \% \mathrm{H}_{2} \mathrm{O}$ to $100 \% \mathrm{D}_{2} \mathrm{O}$. Consequently, the $\mathrm{KSIE}_{1 \mathrm{O} 2}$ is very sensitive to the exact fraction of $\mathrm{D}_{2} \mathrm{O}$ in experimental solutions. These

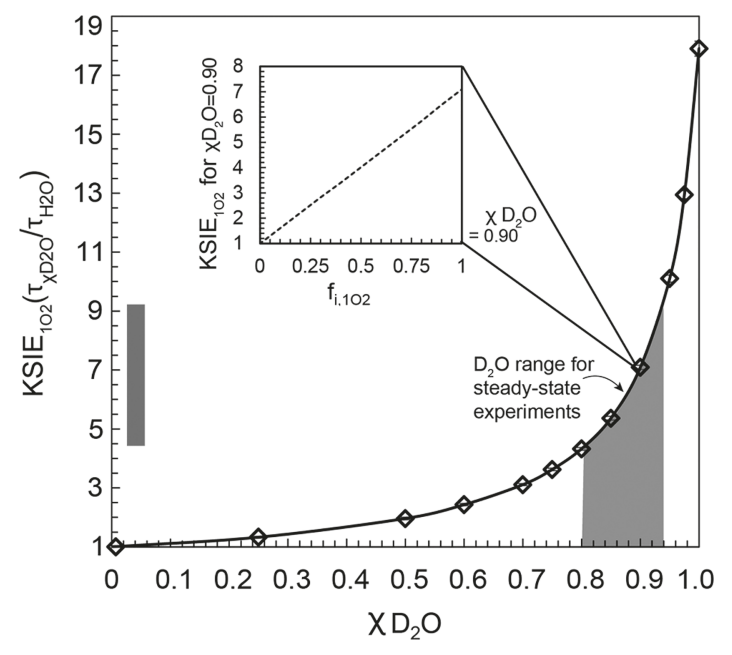

Figure 3. Kinetic solvent isotope effect, KSIE, as the ratio of singlet oxygen, ${ }^{1} \mathrm{O}_{2}$, lifetimes in heavy over light water, $\tau_{\chi \mathrm{D} 2 \mathrm{O}} / \tau_{\mathrm{H} 2 \mathrm{O}}$, in relation to the fraction of $\mathrm{D}_{2} \mathrm{O}$ in solution $\left(\chi \mathrm{D}_{2} \mathrm{O}\right)$. Data follows an inverse relationship: $\mathrm{KSIE}=\left[-0.942 \cdot\left(\chi \mathrm{D}_{2} \mathrm{O}\right)+0.988\right]^{-1}$ as determined by time-resolved infrared luminescence spectroscopy with detection at $1270 \mathrm{~nm}$. The shaded area under the curve indicates the range of $\mathrm{D}_{2} \mathrm{O}$ (mole fraction, $\chi$ ) determined in the presented experiments using DOM as the triplet sensitizer (data in Figure 2). The inset shows, for a fixed $\chi \mathrm{D}_{2} \mathrm{O}$ of 0.90 , how the estimated $\mathrm{KSIE}_{1 \mathrm{O} 2}$ decreases with the fraction of singlet oxygen-based decay of compound of interest $\left(f_{\mathrm{i}, 1 \mathrm{O} 2}\right)$ and when no other reaction contributes to the observed $\mathrm{KSIE}_{\text {obs }}$.

values are in general agreement with the literature values compiled by Wilkinson et al. in the review of ${ }^{1} \mathrm{O}_{2}$ lifetimes and decay rate constants in a multitude of solvents, ranging from $44-70 \mu \mathrm{s}$ in $\mathrm{D}_{2} \mathrm{O}\left(k_{\mathrm{d}}{ }^{1 \mathrm{O} 2}=1.4-2.3 \times 10^{4} \mathrm{~s}^{-1}\right)$ and 3.1-4.2 $\mu \mathrm{s}$ in $\mathrm{H}_{2} \mathrm{O}\left(k_{\mathrm{d}}{ }^{1 \mathrm{O} 2}=2.4-3.2 \times 10^{5} \mathrm{~s}^{-1}\right)$. $^{21,42}$

The influence of ${ }^{1} \mathrm{O}_{2}$ on $\mathrm{KSIE}_{\text {obs }}$ depends on the fraction of $\mathrm{D}_{2} \mathrm{O}$ present and contribution of ${ }^{1} \mathrm{O}_{2}$ to the overall degradation $\left(f_{\mathrm{i}, 1 \mathrm{O} 2}\right)$. Therefore, the fractions of $\mathrm{D}_{2} \mathrm{O}$ were assessed with the $\mathrm{KSIE}_{\text {obs }}$ determined for FFA for which $f_{\mathrm{i}, 1 \mathrm{O} 2}=1$ and its decay kinetics are directly proportional to the ${ }^{1} \mathrm{O}_{2}$ lifetime, which in turn is a function of the concentration of $\mathrm{D}_{2} \mathrm{O}$ (details see Davis et al. 2017, Text S2). ${ }^{35}$ In the steady-state experiments with DOM, the fraction of $\mathrm{D}_{2} \mathrm{O}$ ranged from 0.81 to 0.94 (Table $\mathrm{S} 1$, shaded area at $\mathrm{x}$-axis in Figure 3). These $\mathrm{D}_{2} \mathrm{O}$ compositions result in maximum $\mathrm{KSIE}_{1 \mathrm{O} 2}$ values ranging from 4.4 to 10 for compounds exclusively reacting with ${ }^{1} \mathrm{O}_{2}$, like FFA (shaded bar at $y$-axis in Figure 3 ). Second, $f_{\mathrm{i}, 1 \mathrm{O} 2}$ was assessed for each fenamate and diclofenac according to eq 2 . The reactions with ${ }^{1} \mathrm{O}_{2}$ contributed up to $19 \%$ for mefenamic acid and $8-16 \%$ for the other diarylamines to the overall decay, while no ${ }^{1} \mathrm{O}_{2}$ contribution was observed for diclofenac $\left(f_{\mathrm{i}, 1 \mathrm{O} 2}=0.0\right)$. The insert in Figure 3 illustrates how the $\mathrm{KSIE}_{1 \mathrm{O} 2}$ can vary for compounds with a different $f_{\mathrm{i}, 1 \mathrm{O} 2}$ shown for a fixed $\chi \mathrm{D}_{2} \mathrm{O}$ of 0.90 . The low $f_{\mathrm{i}, 1 \mathrm{O} 2}$ values $(<0.2)$ for diarylamines explain why relatively low $\mathrm{KSIE}_{1 \mathrm{O} 2}$ values can be expected from the reaction with ${ }^{1} \mathrm{O}_{2}$ alone.

Contribution of Non- ${ }^{1} \mathrm{O}_{2}$ Pathways to $\mathrm{KSIE}_{\text {obs. }}$. The overall observed degradation rate is the superposition of degradation resulting from several different pathways. To assess potential contribution of other reaction pathways to the $\mathrm{KSIE}_{\mathrm{obs}}$, the estimated $\mathrm{KSIE}_{1 \mathrm{O} 2}$ values were subtracted from the $\mathrm{KSIE}_{\mathrm{obs}}$ values determined experimentally (data in Figure 2D). For most compounds, a significant contribution of a non- ${ }^{1} \mathrm{O}_{2}$ related KSIE was evident. 
Data in Figure 4 show the $\mathrm{KSIE}_{\mathrm{obs}}$ values measured in the presence of DOM (10 $\left.\mathrm{mg}_{\mathrm{C}} \mathrm{L}^{-1} \mathrm{SRFA}\right)$ with the relative

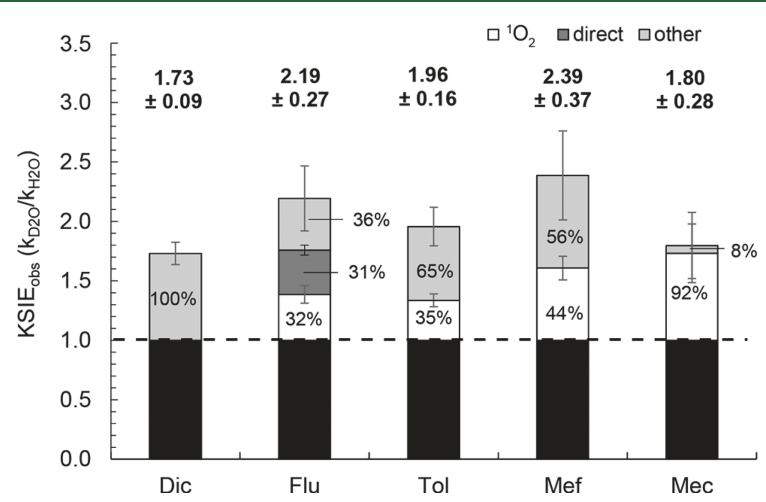

Figure 4. Kinetic solvent isotope effect, KSIE, as the ratio of pseudofirst-order degradation rate constants, in heavy over light water, $k_{\mathrm{D} 2 \mathrm{O}} /$ $k_{\mathrm{H} 2 \mathrm{O}}$. The black dashed horizontal line represents the threshold where no enhancement in $\mathrm{D}_{2} \mathrm{O}$ is observed $\left(k_{\mathrm{D} 2 \mathrm{O}} / k_{\mathrm{H} 2 \mathrm{O}}=1.0\right)$. The portion above 1.0 is broken down into contributing degradation pathways. White bars show the contribution from reaction with singlet oxygen, ${ }^{1} \mathrm{O}_{2}$, ranging from 0 to $92 \%$. The dark gray bar shows the contribution from direct photodegradation, only applying to flufenamic acid (Flu, $31 \%)$. Light gray bars show the contribution from other reaction pathways, ranging from 8 to $100 \%$. Error bars represent one standard deviation.

contribution of ${ }^{1} \mathrm{O}_{2}$ and other degradation pathways (stacked bars above KSIE = 1). The $\mathrm{KSIE}_{\mathrm{obs}}$ values ranged from 1.7 to 2.4 but could only partially be attributed to the reaction with ${ }^{1} \mathrm{O}_{2}$. The contribution of "other" processes to $\mathrm{KSIE}_{\text {obs }}$ was highest for diclofenac (100\%), which does not react with ${ }^{1} \mathrm{O}_{2}$ and ranged from 56 to $65 \%$ for mefenamic acid, flufenamic acid, and tolfenamic acid. The overall $\mathrm{KSIE}_{\mathrm{obs}}$ for meclofenamic acid was 1.8 , of which $92 \%$ can be attributed to the reaction with ${ }^{1} \mathrm{O}_{2}$ and only a minor contribution coming from other processes $(8 \%)$. This observation is supported by our previous finding, that, among these fenamates, meclofenamic acid has the greatest bimolecular reaction rate constant with ${ }^{1} \mathrm{O}_{2}\left(2.8 \times 10^{7} \mathrm{M}^{-1} \mathrm{~s}^{-1}\right)$ and also exhibited the slowest bimolecular reaction rate constants with the model antioxidant ascorbic acid $\left(3.3 \times 10^{7} \mathrm{M}^{-1} \mathrm{~s}^{-1}\right)$. Direct photochemical degradation contributed to the $\mathrm{KSIE}_{\text {obs }}$ only for flufenamic acid (Figure S11). Contrary to the other diarylamines studied, flufenamic acid is known to undergo direct photochemical transformation under experimental conditions (i.e., irradiance with $365 \mathrm{~nm}$ ) by photohydrolysis of the trifluoromethyl group, ${ }^{43}$ which evidently proceeds faster in $\mathrm{D}_{2} \mathrm{O}$. The rate of direct photodegradation is dependent on the rate of light absorbance by the compound of interest and the quantum yield for a transformation reaction. If one of these parameters changes in $\mathrm{D}_{2} \mathrm{O}$-enriched solution, direct phototransformation may contribute an additional KSIE. Absorbance spectra for all compounds can be found in the SI (Figures S12 and S13). The mechanistic investigation of a KSIE from direct photochemical transformation pathways is compound specific and therefore beyond the scope of this work.

In the following we demonstrate that the additional degradation enhancement in $\mathrm{D}_{2} \mathrm{O}$ can most likely be attributed to the reduction of radical intermediates rather than the reaction with the triplet sensitizer (i.e., effect on triplet lifetime or reactivity).
KSIE from Reduction Reaction of Radical Intermediates. To investigate effect of reductants toward the $\mathrm{KSIE}_{\mathrm{obs}}$, we first investigated the isotope effect associated with a phenolic antioxidant, representative of phenolic DOM moieties. Additionally, we evaluated the role of superoxide as a reductant.

Radical intermediates of mefenamic acid were generated from the reaction with triplet excited lumichrome, ${ }^{3} \mathrm{LC} *$. Mefenamic radical decay was monitored in the presence of a phenolic antioxidant, sesamol, in $100 \% \mathrm{H}_{2} \mathrm{O}$ and $100 \% \mathrm{D}_{2} \mathrm{O}$ by time-resolved transient absorption spectroscopy. Data in Figure 5 show increasing decay rate constants of the

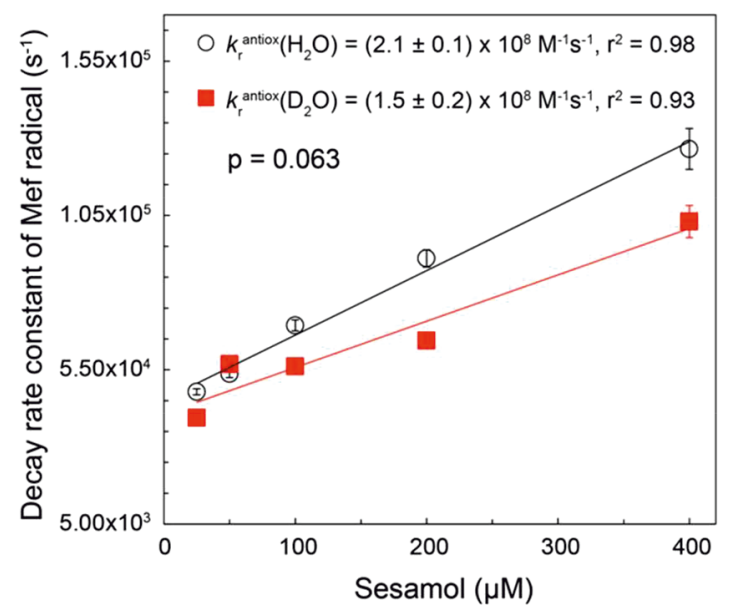

Figure 5. Stern-Volmer plot of the decay rate constant of the mefenamic acid (Mef) radical signal in the presence of varying concentrations of sesamol (antioxidant) in light water $\left(\mathrm{H}_{2} \mathrm{O}\right.$, black open circles) and in heavy water $\left(\mathrm{D}_{2} \mathrm{O}\right.$, red filled squares). Shown are the second-order reaction rate constants, $k_{r}^{\text {antiox }}$, determined from linear regression and the p-value ( $t$ test). Error bars represent one standard deviation.

mefenamic acid radical intermediate with increasing concentrations sesamol. The second-order reaction rate constants, $k_{\mathrm{r}}^{\text {antiox }}$, were assessed in $\mathrm{H}_{2} \mathrm{O}$ and $\mathrm{D}_{2} \mathrm{O}$ by linear regression. The experimental KSIE $\left(k_{\mathrm{H} 2 \mathrm{O}} / k_{\mathrm{D} 2 \mathrm{O}}\right)$ was $1.39 \pm 0.23$, consequently, the reactivity of the radical intermediate with the antioxidant was slightly slower in $\mathrm{D}_{2} \mathrm{O}$ ( $t$ test, $p=0.063$ ). Sesamol has a relatively low BDFE, making it a strong antioxidant, leading to fast PCET. Previous studies investigating (PC)ETs reported lower isotope effects for compounds with higher reaction rate constants. ${ }^{28,44}$ Reported isotope effects for the oxidation of phenol with humic and fulvic acids and triplet sensitizer, benzophenone were within a similar range $(0.7-1.7) .^{26}$

While the absolute KSIE from the reaction of radical intermediates with antioxidants is relatively small, it was the only process in the hypothesized reactions scheme (Figure 1) that demonstrated a KSIE. The reduction of the radical intermediate back to the parent compound can only contribute significantly to the $\mathrm{KSIE}_{\mathrm{obs}}$ when this pathway is kinetically favorable. Consequently, the relative contribution of the antioxidant pathways is assumed to be high under the presented conditions. No KSIE was observed regarding the triplet lifetime and reactivity with model triplet sensitizers as detailed below.

Superoxide radical anions $\left(\mathrm{O}_{2}{ }^{--}\right)$are formed from electron transfer reactions from sensitizers to molecular oxygen and can 
not only act as oxidants (e.g., toward diphenols) or nucleophiles (e.g., toward typical SN2 substrates) but also as one-electron reducing agents in aprotic solutions toward organic compounds. ${ }^{45}$ Here, $\mathrm{O}_{2}{ }^{--}$did not contribute significantly to the overall photodegradation. The reaction kinetics of diclofenac in $\mathrm{H}_{2} \mathrm{O}$ showed no change when $\mathrm{O}_{2}{ }^{\bullet-}$ was quenched by superoxide dismutase (SOD), an enzyme that catalyzes the dismutation of $\mathrm{O}_{2}{ }^{\bullet-}$ to molecular oxygen and hydrogen peroxide (Figures S14 and S15). However, an increased degradation was observed in the presence of SOD in $90 \% \mathrm{D}_{2} \mathrm{O}(k($ withSOD $) / k$ (withoutSOD $)=1.63 \pm 0.23, t$ test, $p<0.05)$. We hypothesize that $\mathrm{O}_{2}{ }^{--}$could also be formed through the reduction of ${ }^{1} \mathrm{O}_{2}$, in which case more would be produced under $\mathrm{D}_{2} \mathrm{O}$ enriched conditions. Further tests to quantify the steady-state concentration $\mathrm{O}_{2}{ }^{\bullet-}$ would be needed to evaluate this hypothesis.

No KSIE on Triplet Lifetimes and Reactivity. Three model triplet sensitizers were selected to investigate a potential KSIE on triplet lifetimes, $\tau$. Lumichrome was selected as a model sensitizer for its potential $\mathrm{H} / \mathrm{D}$ exchange at the amino protons and 3 '-methoxyacetophenone for its potential ketoenol tautomerization chemistry (Figure S16). Perinaphthenone was selected as a model aromatic ketone with no exchangeable protons (negative control). First, ${ }^{1} \mathrm{H} \mathrm{NMR}$ and ${ }^{13} \mathrm{C}\left\{{ }^{1} \mathrm{H}\right\} \mathrm{NMR}$ spectroscopy were performed for 3-MAP to confirm the exchange of deuterium from the solvent (see Figures S1-S4). The incorporation of deuterium into the 3-MAP was basecatalyzed, and full incorporation only took place under highly basic conditions $(\mathrm{pD}=13.6)$. High-resolution mass spectrometry was used to confirm the H/D exchange for lumichrome by the expected mass shift (see Figures S5 and S6). No KSIE on the triplet lifetimes was observed under ambient (air-sparged) conditions (Figure S16, $\tau_{\mathrm{D} 2 \mathrm{O}} / \tau_{\mathrm{H} 2 \mathrm{O}}=1.04 \pm 0.03,1.09 \pm 0.16$, $1.04 \pm 0.03$, and $1.02 \pm 0.03$ for lumichrome, $3-\mathrm{MAP} \mathrm{pH} / \mathrm{D}=$ 8.0, 3-MAP $\mathrm{pH} / \mathrm{pD}=13.6$, and perinaphthenone, respectively). A significant lifetime enhancement in $\mathrm{D}_{2} \mathrm{O}$ was only observed for 3-MAP under argon-sparged conditions, at basic $\mathrm{pH} / \mathrm{pD}\left(\tau_{\mathrm{D} 2 \mathrm{O}} / \tau_{\mathrm{H} 2 \mathrm{O}}=2.35 \pm 0.20\right)$. KSIE $=1.06 \pm 0.03,1.07$ $\pm 0.15,1.14 \pm 0.04$ for lumichrome, 3-MAP $(\mathrm{pH} / \mathrm{pD}=8.0)$ and perinaphthenone, under argon-sparged conditions, respectively.

The reactivity of excited state triplets was investigated as another potential source of a non $-{ }^{1} \mathrm{O}_{2}$ KSIE. Therefore, the

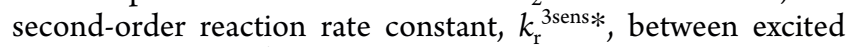
state lumichrome, ${ }^{3} \mathrm{LC}^{*}$, and mefenamic acid was determined by monitoring the decay rate constant of ${ }^{3} \mathrm{LC}^{*}$ in the presence of increasing concentrations of mefenamic acid as a quencher. No significant change in $k_{\mathrm{r}}^{3 \text { sens } *}$ was observed from $5.25 \pm 0.27$ $\mathrm{M}^{-1} \mathrm{~s}^{-1}$ in $\mathrm{H}_{2} \mathrm{O}$ to $4.66 \pm 0.21 \mathrm{M}^{-1} \mathrm{~s}^{-1}$ in $\mathrm{D}_{2} \mathrm{O}$ ( $t$ test, $p=$ 0.09 , Figure S17). Consequently, the non- ${ }^{1} \mathrm{O}_{2} \mathrm{KSIE}$ for photodecay of diarylamines and diclofenac is neither related to a change in triplet sensitizer lifetime nor its reactivity but is ascribed to the decelerated repair of the radical intermediates by antioxidant moieties in DOM.

\section{IMPLICATIONS}

In light of the findings of a non- ${ }^{1} \mathrm{O}_{2}$ related KSIE in environmental photochemical studies, we conclude that the KSIE method is not only a reasonable test for probing the reactivity of a compound with ${ }^{1} \mathrm{O}_{2}$ but can even offer evidence for a quenchable radical intermediate step of the degradation pathway. First, one should be mindful that changing the solvent can affect other reaction pathways and not only the lifetime of ${ }^{1} \mathrm{O}_{2}$. Compounds that are oxidized by triplet excited molecules and transition through a radical intermediate are likely to exhibit an additional KSIE as demonstrated for diclofenac and diarylamines. Here, the additional KSIE is attributed to the reduction reaction of the radical intermediates with suitable antioxidant by a (PC)ET reaction. The likelihood that these reactions occur during environmental photochemistry is high, as oxidizing moieties in natural CDOM can act as the sensitizer and phenolic moieties in DOM can act as the antioxidant. While the absolute KSIE may be relatively small, we demonstrate that the process can contribute significantly to the overall $\mathrm{KSIE}_{\mathrm{obs}}$ when a repairable reaction with triplets is a dominant decay pathway. Comparing observed decay rate constants in $\mathrm{D}_{2} \mathrm{O}$ and $\mathrm{H}_{2} \mathrm{O}$ to determine second-order reaction rate constants with ${ }^{1} \mathrm{O}_{2}$ should only be used when one of the following criteria are fulfilled: (a) degradation does not proceed through a reducible radical intermediate, or (b) there are no reducing agents present in the solution. One should also include controls to determine potential effects of other pathways, e.g., direct photodegradation, toward the $\mathrm{KSIE}_{\mathrm{obs}}$.

\section{ASSOCIATED CONTENT}

\section{S Supporting Information}

The Supporting Information is available free of charge on the ACS Publications website at DOI: 10.1021/acs.est.8b01512.

Tables S1 and S2, Texts S1 and S2, Figures S1-S17 (PDF)

\section{AUTHOR INFORMATION}

\section{Corresponding Authors}

*Phone: + 4158765 5802. E-mail: elisabeth.janssen@eawag. ch (E.M.-L.J.).

*Phone: +41 44632 3755. E-mail: kris.mcneill@env.ethz.ch (K.M.).

ORCID

Kristopher McNeill: 0000-0002-2981-2227

Elisabeth M.-L. Janssen: 0000-0002-5475-6730

\section{Notes}

The authors declare no competing financial interest.

\section{ACKNOWLEDGMENTS}

We gratefully acknowledge support of the Swiss National Science Foundation (Grant number 200021-156198). We thank Dr. Paul Erickson and Markus Schmitt for support with the transient absorption spectroscopy experiments, Dr. Kyle Moor for support with the ${ }^{1} \mathrm{O}_{2}$ phosphorescence experiment, and Dr. Thomas Hofstetter and Dr. Silvio Canonica for fruitful discussions.

\section{REFERENCES}

(1) Shao, C. W.; Cooper, W. J.; Lean, D. R. S. Singlet Oxygen Formation in Lake Waters from Midlatitudes. Aquatic and Surface Photochemistry 1994, 215-221.

(2) Wick, L. Y.; McNeill, K.; Rojo, M.; Medilanski, E.; Gschwend, P. M. Fate of benzene in a Stratified Lake receiving contaminated groundwater discharges from a Superfund site. Environ. Sci. Technol. 2000, 34 (20), 4354-4362.

(3) Wolff, C. J. M.; Halmans, M. T. H.; Vanderheijde, H. B. The Formation of Singlet Oxygen in Surface Waters. Chemosphere 1981, 10 (1), 59-62. 
(4) Wolfe, N. L.; Zepp, R. G.; Gordon, J. A.; Baughman, G. L.; Cline, D. M. Kinetics of Chemical Degradation of Malathion in Water. Environ. Sci. Technol. 1977, 11 (1), 88-93.

(5) Herzberg, L.; Herzberg, G. Fine Structure of the Infrared Atmospheric Oxygen Bands. Astrophys. J. 1947, 105 (3), 353.

(6) Zepp, R. G.; Schlotzhauer, P. F.; Sink, R. M. Photosensitized Transformations Involving Electronic-Energy Transfer in NaturalWaters - Role of Humic Substances. Environ. Sci. Technol. 1985, 19 (1), 74-81.

(7) McNeill, K.; Canonica, S. Triplet state dissolved organic matter in aquatic photochemistry: reaction mechanisms, substrate scope, and photophysical properties. Environ. Sci.: Processes Impacts 2016, 18 (11), 1381-1399.

(8) Larson, R. A.; Weber, E. J. Reaction Mechanisms in Environmental Organic Chemistry. CRC Press: 1994.

(9) Boreen, A. L.; Arnold, W. A.; McNeill, K. Triplet-sensitized photodegradation of sulfa drugs containing six-membered heterocyclic groups: Identification of an $\mathrm{SO} 2$ extrusion photoproduct. Environ. Sci. Technol. 2005, 39 (10), 3630-3638.

(10) Latch, D. E.; Stender, B. L.; Packer, J. L.; Arnold, W. A.; McNeill, K. Photochemical fate of pharmaceuticals in the environment: Cimetidine and ranitidine. Environ. Sci. Technol. 2003, 37 (15), $3342-3350$.

(11) Foote, C. S. Photosensitized Oxygenations and Role of Singlet Oxygen. Acc. Chem. Res. 1968, 1 (4), 104.

(12) Haag, W. R.; Hoigne, J.; Gassman, E.; Braun, A. M. Singlet Oxygen in Surface Waters 0.1. Furfuryl Alcohol as a Trapping Agent. Chemosphere 1984, 13 (5-6), 631-640.

(13) Scully, F. E.; Hoigne, J. Rate Constants for Reactions of Singlet Oxygen with Phenols and Other Compounds in Water. Chemosphere 1987, 16 (4), 681-694.

(14) Appiani, E.; Ossola, R.; Latch, D. E.; Erickson, P. R.; McNeill, $\mathrm{K}$. Aqueous singlet oxygen reaction kinetics of furfuryl alcohol: effect of temperature, $\mathrm{pH}$, and salt content. Environ. Sci.: Processes Impacts 2017, 19 (4), 507-516.

(15) Boreen, A. L.; Edhlund, B. L.; Cotner, J. B.; McNeill, K. Indirect photodegradation of dissolved free amino acids: The contribution of singlet oxygen and the differential reactivity of DOM from various sources. Environ. Sci. Technol. 2008, 42 (15), 5492-5498.

(16) Xu, H. M.; Cooper, W. J.; Jung, J.; Song, W. H. Photosensitized degradation of amoxicillin in natural organic matter isolate solutions. Water Res. 2011, 45 (2), 632-638.

(17) Razavi, B.; Ben Abdelmelek, S.; Song, W. H.; O'Shea, K. E.; Cooper, W. J. Photochemical fate of atorvastatin (lipitor) in simulated natural waters. Water Res. 2011, 45 (2), 625-631.

(18) Wang, L.; Xu, H. M.; Cooper, W. J.; Song, W. H. Photochemical fate of beta-blockers in NOM enriched waters. Sci. Total Environ. 2012, 426, 289-295.

(19) Yang, W. L.; Ben Abdelmelek, S.; Zheng, Z.; An, T. C.; Zhang, D. N.; Song, W. H. Photochemical transformation of terbutaline (pharmaceutical) in simulated natural waters: Degradation kinetics and mechanisms. Water Res. 2013, 47 (17), 6558-6565.

(20) Janssen, E. M. L.; Erickson, P. R.; McNeill, K. Dual Roles of Dissolved Organic Matter as Sensitizer and Quencher in the Photooxidation of Tryptophan. Environ. Sci. Technol. 2014, 48 (9), 4916-4924.

(21) Nonell, S.; Flors, C. Steady-State and Time-Resolved Singlet Oxygen Phosphorescence Detection in the Near-IR. Compr Ser. Photoch 2016, 2, 7-26.

(22) Scaiano, J. C. CRC handbook of organic photochemistry; CRC Press: Boca Raton, FL, 1989.

(23) Merkel, P. B.; Kearns, D. R. Radiationless Decay of Singlet Molecular-Oxygen in Solution - Experimental and Theoretical Study of Electronic-to-Vibrational Energy-Transfer. J. Am. Chem. Soc. 1972, 94 (21), 7244-7253.

(24) Abdel-Shafi, A. A.; Hassanin, H. A.; Al-Shihry, S. S. Partial charge transfer contribution to the solvent isotope effect and photosensitized generation of singlet oxygen, $\mathrm{O}_{2}\left({ }^{1} \Delta_{\mathrm{g}}\right)$, by substituted
ruthenium(II) bipyridyl complexes in aqueous media. Photoch Photobio Sci. 2014, 13 (9), 1330-1337.

(25) Alarcon, E. I.; Gonzalez-Bejar, M.; Montes-Navajas, P.; Garcia, H.; Lissi, E. A.; Scaiano, J. C. Unexpected solvent isotope effect on the triplet lifetime of methylene blue associated to cucurbit[7]uril. Photoch Photobio Sci. 2012, 11 (2), 269-273.

(26) Canonica, S.; Jans, U.; Stemmler, K.; Hoigne, J. Transformation Kinetics of Phenols in Water - Photosensitization by Dissolved Natural Organic Material and Aromatic Ketones. Environ. Sci. Technol. 1995, 29 (7), 1822-1831.

(27) Rhile, I. J.; Markle, T. F.; Nagao, H.; DiPasquale, A. G.; Lam, O. P.; Lockwood, M. A.; Rotter, K.; Mayer, J. M. Concerted protonelectron transfer in the oxidation of hydrogen-bonded phenols. J. Am. Chem. Soc. 2006, 128 (18), 6075-6088.

(28) Erickson, P. R.; Walpen, N.; Guerard, J. J.; Eustis, S. N.; Arey, J. S.; McNeill, K. Controlling Factors in the Rates of Oxidation of Anilines and Phenols by Triplet Methylene Blue in Aqueous Solution. J. Phys. Chem. A 2015, 119 (13), 3233-3243.

(29) Bent, D. V.; Hayon, E. Excited-State Chemistry of Aromatic Amino-Acids and Related Peptides 0.3. Tryptophan. J. Am. Chem. Soc. 1975, 97 (10), 2612-2619.

(30) Leresche, F.; von Gunten, U.; Canonica, S. Probing the Photosensitizing and Inhibitory Effects of Dissolved Organic Matter by Using N,N-dimethyl-4-cyanoaniline (DMABN). Environ. Sci. Technol. 2016, 50, 10997-11007.

(31) Canonica, S.; Laubscher, H. U. Inhibitory effect of dissolved organic matter on triplet-induced oxidation of aquatic contaminants. Photoch Photobio Sci. 2008, 7 (5), 547-551.

(32) Zhou, L.; Ji, Y. F.; Zeng, C.; Zhang, Y.; Wang, Z. Y.; Yang, X. Aquatic photodegradation of sunscreen agent $\mathrm{p}$-aminobenzoic acid in the presence of dissolved organic matter. Water Res. 2013, 47 (1), $153-162$.

(33) Wenk, J.; Canonica, S. Phenolic Antioxidants Inhibit the Triplet-Induced Transformation of Anilines and Sulfonamide Antibiotics in Aqueous Solution. Environ. Sci. Technol. 2012, 46 (10), $5455-5462$.

(34) Zeng, T.; Arnold, W. A. Pesticide Photolysis in Prairie Potholes: Probing Photosensitized Processes. Environ. Sci. Technol. 2013, 47 (13), 6735-6745.

(35) Davis, C. A.; Erickson, P. R.; McNeill, K.; Janssen, E. M. Environmental photochemistry of fenamate NSAIDs and their radical intermediates. Environ. Sci.: Processes Impacts 2017, 19, 656-665.

(36) Aeschbacher, M.; Graf, C.; Schwarzenbach, R. P.; Sander, M. Antioxidant Properties of Humic Substances. Environ. Sci. Technol. 2012, 46 (9), 4916-4925.

(37) Reemtsma, T.; Weiss, S.; Mueller, J.; Petrovic, M.; Gonzalez, S.; Barcelo, D.; Ventura, F.; Knepper, T. P. Polar pollutants entry into the water cycle by municipal wastewater: A European perspective. Environ. Sci. Technol. 2006, 40 (17), 5451-5458.

(38) Michael, I.; Rizzo, L.; McArdell, C. S.; Manaia, C. M.; Merlin, C.; Schwartz, T.; Dagot, C.; Fatta-Kassinos, D. Urban wastewater treatment plants as hotspots for the release of antibiotics in the environment: A review. Water Res. 2013, 47 (3), 957-995.

(39) Luo, Y. L.; Guo, W. S.; Ngo, H. H.; Nghiem, L. D.; Hai, F. I.; Zhang, J.; Liang, S.; Wang, X. C. C. A review on the occurrence of micropollutants in the aquatic environment and their fate and removal during wastewater treatment. Sci. Total Environ. 2014, 473-474, 619641.

(40) Petrie, B.; Barden, R.; Kasprzyk-Hordern, B. A review on emerging contaminants in wastewaters and the environment: Current knowledge, understudied areas and recommendations for future monitoring. Water Res. 2015, 72, 3-27.

(41) Tse, R. S.; Wong, S. C.; Yuen, C. P. Determination of Deuterium-Hydrogen Ratios in Natural-Waters by Fourier-Transform Nuclear Magnetic-Resonance Spectrometry. Anal. Chem. 1980, 52 (14), 2445-2445.

(42) Wilkinson, F.; Helman, W. P.; Ross, A. B. Rate Constants for the Decay and Reactions of the Lowest Electronically Excited Singlet- 
State of Molecular-Oxygen in Solution - an Expanded and Revised Compilation. J. Phys. Chem. Ref. Data 1995, 24 (2), 663-1021.

(43) Rafqah, S.; Sarakha, M. Photochemical transformation of flufenamic acid by artificial sunlight in aqueous solutions. $J$. Photochem. Photobiol., A 2016, 316, 1-6.

(44) Shirota, H.; Pal, H.; Tominaga, K.; Yoshihara, K. Substituent effect and deuterium isotope effect of ultrafast intermolecular electron transfer: Coumarin in electron-donating solvent. J. Phys. Chem. A 1998, 102 (18), 3089-3102.

(45) Hayyan, M.; Hashim, M. A.; AlNashef, I. M. Superoxide Ion: Generation and Chemical Implications. Chem. Rev. 2016, 116 (5), $3029-3085$. 